\title{
ИСКЛЮЧЕНИЯ ИЗ ПРИНЦИПА ОТКРЫТОСТИ ИНФОРМАЦИИ О ДЕЯТЕЛЬНОСТИ ГОСУДАРСТВЕННЫХ ОРГАНОВ
}

\author{
В. В. Силкин \\ Наииональный исследовательский университет \\ "Высшая школа эконолики» \\ Поступила в редакцию 7 июля 2020 г.
}

\begin{abstract}
Аннотация: расслотрены особенности ограничения доступа к инфборлаиии о деятельности государственных органов. Особо уделено внимание понятию слешанных режимов инфборлации, опосредующих конббликт открытости и конфбиенииальности при предоставлении государственнылии органали инфборлации. Сделан вывод, что в слешанных режилах по общему правилу соблюдается приоритет конфиденииальности, предполагающий изъятие данных ограниченного доступа из предоставляелой государственныли органол инфборлаиии. В качестве отдельных альтернативных полномочий должностных лиц в ралках слешанного режила выделены также опубликование сведений ограниченного доступа в общественно значилых иелях и предоставление доступа к такил сведениял при условии удостоверения личности заявителя без размещения данных в открытол доступе.

Ключевые слова: правовой режил инфорлаиии, конфбиденииальность инфорлаиии, открытое правительство, публичный интерес, открытость инбормаиии.
\end{abstract}

Abstract: the article focuses on the peculiarities of the limitation of the access to the information held by public bodies. Special attention is paid to the concept of the mixed regimes in Russian law, dealing with the conflict between the openness and the confidentiality of the public sector information. The general rule for the disclosure keeps the confidentiality and provides for the anonymization or erasure of the protected parts of the data disclosed. There are also supplementary options: disclosing the data of limited access in public interests and the establishment of identification procedures for the claimants.

Key words: public sector information, open government, re-use of public sector information, confidentiality, openness.

164 Открытость и доступность информации о деятельности государственных органов установлена в качестве одного из основополагающих принципов в российском законодательстве ${ }^{1}$. Если в российской правовой доктрине большее внимание уделяется открытой информации, открытым данным либо конфиденциальной информации и тайнам, то вопрос соотношения принципа открытости и исключений из него исследован меньше, в частности незначительно изучен набор прав и обязанностей должностных лиц государственных органов в отношении раскрываемой информации, ча-

${ }^{1}$ Об обеспечении доступа к информации о деятельности государственных органов и органов местного самоуправления : федер. закон от 9 февраля 2009 г. № 8-ФЗ // Рос. газета. 2009. 13 февр.

(C) Силкин В. В., 2021 
стично содержащей данные ограниченного доступа. Теоретическое осмысление указанной проблемы возможно в рамках исследования смешанных режимов информации о деятельности государственных органов.

В российской правовой доктрине было выработано понятие правового режима информации, позволяющее обратить внимание на совокупность обязанностей и прав субъектов правового режима в отношении такой информации, как объект правового режима. Основные положения о содержании правовых режимов информащии наиболее полно были сорормулированы Л. К. Терещенко. Автор выделила следующие элементы содержания правового режима информации: целевое назначение, объект правового регулирования, правовое положение субъектов, комплекс способов правового регулирования и средств юридического воздействия ${ }^{2}$. Концепция правового режима автора поддерживается и в других исследованиях ${ }^{3}$.

На основе указанных критериев можно выделить традиционные правовые режимы общедоступной информации и информации ограниченного доступа. Одновременно информация, содержащая как общедоступные сведения, так и сведения ограниченного доступа, редко рассматривается в качестве отдельного объекта правового режима. Аналогично и в зарубежной литературе вопросы разграничения общедоступности и конфиденциальности информации о деятельности государственных органов освещаются в основном в рамках рассмотрения ограничений доступа к информации государственных органов ${ }^{4}$.

В российской правовой литературе для характеристики указанной проблемы было использовано понятие «смешанные режимы» ${ }^{5}$, которое, однако, не получило достаточного теоретического осмысления. Развитие понятия смешанных режимов - значимое направление исследований реализации механизмов общедоступности и открытости информации государственных органов. Обобщение нормативной базы ограничения доступа к общедоступной информации о деятельности государственных органов позволяет уточнить особенности изъятия данных ограниченного доступа из раскрываемой информации и определить основные обязанности должностных лиц в сфрере обеспечения открытости информации о го-

${ }^{2}$ См.: Терещенко Л. К. Правовой режим информации : автореф. дис. ... д-ра юрид. наук. М., 2011.

${ }^{3}$ См., например: Калалова Г. Г. Правовой режим информации ограниченного доступа : вопросы формирования понятийного аппарата // Вестник Удмуртского ун-та. 2016. Т. 26, вып. 4. С. 118-125 ; Шалаева T. З. Правовой режим информационных ресурсов : проблемы правопонимания // Информационное право. 2014. № 4. С. 4-9 ; Концепция Информационного кодекса Российской Федерации / под ред. И. Л. Бачило. М., 2014. С. 44.

${ }^{4}$ См., например: Canavaggio $P$. Vers un droit d'accès à l'information publique: les avancées récentes des normes et des pratiques. Rabat : UNESCO Office Rabat, 2014 ; Beguin-Faynel C. «Rapport de synthèse». L'open data: une evolution juridique? / Mouriesse E. (dir.) // Revue générale du droit. Etudes et réflexions, 2018, № 11.

${ }^{5}$ См.: Гунин Д. И. Транспарентность и тайна информации : теоретико-правовой аспект : авторефр. дис. ... канд. юрид. наук. Екатеринбург, 2008. 
сударственной деятельности, открытых данных. При этом само понятие правовых режимов информации, сложившееся в российской правовой литературе, позволяет охватить как особенности определения юридической природы информации, так и действия должностных лиц в отношении ее.

Результаты исследования позволяют обобщить особенности установления смешанных режимов, выделить права и обязанности субъектов смешанных режимов по ограничению доступа к информации, предоставляемой для общего доступа.

Более подробно рассмотрим содержание смешанных правовых режимов информации о деятельности государственных органов. Целевое назначение смешанных правовых режимов - предотвращение случайного или намеренного раскрытия информации ограниченного доступа при предоставлении организациям и гражданам информации о деятельности государственных органов. Объект смешанных режимов - информация о деятельности государственных органов, содержащая сведения ограниченного и общего доступа. Основной субъект смешанного режима - должностное лицо государственного органа, в компетенции которого находится разрешение вопроса о предоставлении информации. Комплекс способов правового регулирования и средств юридического воздействия включает в себя отдельные нормы действующего российского законодательства, определяющие порядок разрешения конфликта правовых режимов информации при ее предоставлении и устанавливающие соответствующие меры юридической ответственности должностных лиц.

Для характеристики смешанных режимов предлагается выделить первичный и вторичный режимы информации о деятельности государственных органов. Первичный режим информации характеризует совокупность прав и обязанностей должностных лиц в отношении ин$\sim$ формации ограниченного доступа, находящейся в распоряжении государственного органа. Первичный режим всегда относится к информации ограниченного доступа. Вторичный режим обозначает совокупность прав и обязанностей физических и юридических лиц, получающих доступ к информации о деятельности государственного органа. Похожее деление предлагал и С. С. Алексеев, выделяя первичные режимы, устанавливающие исходные общие средства правового регулирования, и вторичные, носящие определенные уточнения и изменения в первичные ${ }^{6}$.

Под смешанным режимом информации о деятельности государственных органов понимается совокупность установленных в законе средств правового регулирования деятельности должностных лиц органов государственной власти в отношении информации, подлежащей предоставлению гражданам и организациям и содержащей сведения ограниченного доступа.

В целом смешанные режимы информации характеризуются следующими полномочиями государственных органов: изъятие данных огра-

${ }^{6}$ См.: Алексеев C. С. Общие дозволения и общие запреты в советском праве. M., 1989. C. 187. 
ниченного доступа из предоставляемой информации; предоставление общего доступа к информации ограниченного доступа в общественно значимых целях; установление специальных процедур удостоверения личности для получения доступа к открытой информации, содержащей сведения ограниченного доступа.

По общему правилу информация ограниченного доступа изымается из предоставляемых гражданам и организациям данных. Сохраняется первичный режим конфиденциальности для части информации. Содержание смешанного режима информации в данном случае состоит в осуществлении должностными лицами полномочий по сохранению конфиденциальности информации ограниченного доступа.

Так, согласно п. 3 ч. 1 ст. 11 Федерального закона от 9 фревраля 2009 г. № 8-Ф3 «Об обеспечении доступа к информащии о деятельности государственных органов и органов местного самоуправления» при обеспечении доступа к информации о деятельности государственных органов информация ограниченного доступа должна быть изъята. Возможность изъятия информации ограниченного доступа при ее предоставлении подтверждается и судебной практикой.

В качестве примера можно привести апелляционное определение Московского областного суда от 28 фревраля 2013 г. по делу № 33-4859/20137. Заявитель, состоявшая на учете в качестве нуждающегося в жилом помещении, направила в уполномоченный орган местного самоуправления требование предоставить ей сведения о соблюдении очередности распределения жилья, в том числе сведения о распределенных жилых помещениях за указанный ей период, а также о гражданах, которым эти помещения были распределены с уточнением сроков получения ими жилья и оснований его приобретения. Уполномоченный орган ответил отказом, ссылаясь на конфиденциальность персональных данных. Суд первой инстанции установил, что заявитель имела право требовать доступ к сведениям, характеризующим выделенное жилье, и к данным о количестве таких жилых помещений, признал отказ уполномоченного органа неправомерным. Суд апеллящионной инстанции поддержал доводы нижестоящего суда, предписал уполномоченному органу предоставить запрашиваемую информацию с указанием, какие жилые помещения были предоставлены каким гражданам, но с обязательным обезличиванием их персональных данных. Из анализа рассматриваемого дела можно заключить, что, хотя заявитель не могла запросить данные о фиизических лицах, получивших жилье, ей могла быть предоставлена информация, указанная в запросе, с изъятием данных ограниченного доступа. Похожий подход в предписании передавать информацию известен и практике Московского городского суда ${ }^{8}$.

Аналогичные положения можно встретить и в зарубежном праве. Так, во Франции ст. L311-7 Кодекса об отношениях между администрацией и

7 Доступ из справ.-правовой системы «КонсультантПлюс».

8 Определение Московского областного суда от 22 декабря 2011 г. по делу № 33-28457. Доступ из справ.-правовой системы «КонсультантПлюс». 


\section{Вестник ВГУ. Серия: Право}

обществом также устанавливает необходимость изъятия данных ограниченного доступа из предоставляемой информации. В силу ст. L311-1 и L300-2 указанного кодекса полномочиями по предоставлению информации обладают не только сами органы власти, но и юридические лица публичного права, а также юридические лица частного права, на которых возложены публичные обязанности.

Французское право также знает примеры судебной практики, устанавливающей необходимость предоставления запрашиваемых данных с изъятием данных ограниченного доступа. Например, в решении Государственного Совета Франции от 7 июня 2019 г. ${ }^{10}$ было оставлено в силе решение административного трибунала Парижа, предписывающее обществу HLM Antin Résidences предоставить заявителю документы, связанные с поиском асбеста в жилом помещении, с обязательным изъятием данных проживающих.

В другом деле Государственный совет Франции более подробно охарактеризовал обязанность государственного органа устанавливать, возможно ли предоставление требуемых сведений с изъятием данных ограниченного доступа ${ }^{11}$. Организация обратилась к Премьер-министру с требованием предоставить данные об участии государства в покупке акций общества "Аэропорты Лиона». Комиссия доступа к административным документам одобрила предоставление сведений, однако с изъятием данных, составляющих служебную тайну. Из информации, предоставляемой заявителю, были исключены заявки участников конкурса. Административный трибунал Парижа признал такое исключение оправданным. Государственный совет не согласился с административным трибуналом, указав, что последним не было исследовано, можно ли раскрыть сведения о заявках в конкурсе с изъятием части данных или же содержание данных ограниченного доступа такое, что раскрытие в целом невозможно.

Опыт иностранных юрисдикций знает и иные примеры предоставления части данных, не относящихся к данным ограниченного доступа. В Великобритании вся информация о деятельности государственных органов относится к категории «служебной», если для нее не установлен более строгий режим секретности. Для реализации права на доступ к

${ }^{9}$ Code des relations entre le public et l'administration. URL: https:/www.legifrance.gouv.fr/affichCode.do;jsessionid=91C91B1A73A68E15149FA32687E64163. tplgfr34s_2?idSectionTA=LEGISCTA0 00031367685 \& cid Texte=LE GITEXT000031366350\&dateTexte=20190210 (дата обращения: 08.02.2021).

${ }^{10}$ Conseil d'État, 10ème - 9ème chambres réunies, 07/06/2019, 422569. URL: https:// www.legifrance.gouv.fr/ceta/id/CETATEXT000038566436?init=true\&page=1\&query=le+document+est+communiqu \%C3\%A9+au+demandeur+apr\%C3\%A8s+occultation+ou+disjonction+de+ces+mentions.\&searchField=ALL\&tab_selection=all (дата обращения: 08.02.2021).

${ }^{11}$ Conseil d'État, 10ème - 9ème chambres réunies, 27/03/2020, 426623. URL: https:// www.legifrance.gouv.fr/ceta/id/CETATEXT000041781312?init=true\&page=1\&query=le+document+est+communiqu \%C3\%A9+au+demandeur+apr\%C3\%A8s+occultation+ou+disjonction+de+ces+mentions.\&searchField=ALL\&tab_selection=all (дата обращения: 08.02.2021). 
информации устанавливается презумпция, что информация может быть предоставлена заявителю, если только публичный интерес ее предоставления не превышает интерес заявителя в ее получении ${ }^{12}$. Для оспаривания отказа уполномоченным органом в предоставлении информации назначен информационный комиссар, а для оспаривания его решений отдельный информационный трибунал. Практика информационного трибунала представляет особый интерес, поскольку позволяет показать, как в рамках теста публичного интереса определяются части информации, не подлежащей предоставлению.

Например, в деле Фил Миллер против Информационного комиссара, рассмотренном Информационным трибуналом в фреврале 2020 г., ${ }^{13}$ заявитель направил два вопроса, один из которых упоминал конкретных лиц и их участие в подготовке сэром Джереми Хейвудом обзора материалов по обвинению Великобритании в участии в операции индийской армии «Синяя звезда», а второй был более общим, уточняющим, помогал ли кто-то из должностных лиц собрать документы для указанного обзора. Информационный трибунал рассудил, что информация по второму вопросу сводилась к однозначному ответу и не обязывала уполномоченный орган предоставлять конкретные сведения, в связи с чем отказ в ее предоставлении был неправомерным.

Сопоставление Великобритании, Франции и России в данном случае является ключевым, поскольку в Соединенном Королевстве установлен особенный порядок предоставления доступа к информации о деятельности государственных органов, основанный на взвешивании публичных и частных интересов в предоставлении информации. Подход Российской Федерации и Франции основывается на формальном критерии: если информация относится к сведениям ограниченного доступа, она не подлежит раскрытию, если в законе не указано иное. Однако в любой из рассматриваемых юрисдикций сохраняется правило, согласно которому если часть информации может быть предоставлена, такая информация предоставляется с изъятием данных ограниченного доступа.

Таким образом, по общему правилу первичный правовой режим конфиденциальности сохраняется, сведения ограниченного доступа изымаются из предоставляемой государственным органом информации.

В некоторых случаях, однако, правовое регулирование предусматривает исключения из сохранения конфиденциальности информащии при ее раскрытии. К обязательным для опубликования, например, относятся фрамилия, имя и отчество фризических лиц, зарегистрированных в качестве

${ }^{12}$ Ministry of Defence, UK. Access to Information Guidance Note. Version 6 June 2009. Guidance Note E4 The Public Interest Test. URL: https://assets.publishing. service.gov.uk/government/uploads/system/uploads/attachment_data/file/16835/ E420090701MOD_FOI_Guidance_Note.pdf (дата обращения: 08.02.2021).

${ }^{13}$ Phil Miller v IC, Additional Party Foreign \& Commonwealth Office, A/2019/0089, 17.02.2020. URL: https://informationrights.decisions.tribunals.gov.uk/DBFiles/Decision/i2685/Miller,\%20Phil\%20EA.2019.0089\%20\%20(12.03.20).pdf (дата обращения: 08.02.2021). 


\section{Вестник ВГУ. Серия: Право}

индивидуальных предпринимателей ${ }^{14}$. Аналогично п. 5 Правил размещения информации о среднемесячной заработной плате руководителей, их заместителей и главных бухгалтеров государственных внебюджетных фондов Российской Федерации, фредеральных государственных учреждений и федеральных государственных унитарных предприятий, утвержденных постановлением Правительства РФ от 28 декабря 2016 г. № 1521르, предусматривает обязанность внебюджетных фондов, фредеральных государственных унитарных предприятий и фредеральных государственных учреждений размещать в установленном порядке информацию о доходах руководителей таких организаций, их заместителей и главных бухгалтеров с указанием их фрамилии, имени, отчества, а также занимаемой должности.

При этом стоит отметить, что размещаемые в открытом доступе персональные данные сохраняют правовой режим конфриденциальности и не являются общедоступными. Об отсутствии основания использовать персональные данные, размещенные в открытых источниках, суды отмечали и ранее ${ }^{16}$. В настоящее время с принятием Федерального закона от 30 декабря 2020 г. № 519-Ф3 «О внесении изменений в Федеральный закон «О персональных данных» ${ }^{17}$ каждое лицо, получившее доступ к персональным данным, размещенным в открытом доступе, должно самостоятельно доказывать правомерность обработки им таких данных.

Наконец, в некоторых случаях сведения не размещаются в открытом доступе, однако могут быть предоставлены любому заявителю при условии прохождения им процедуры удостоверения личности. Например, сведения о месте регистрации в качестве индивидуального предпринимателя не размещаются в общем доступе, но могут быть получены с предъявлением паспорта по запросу заявителя (ч. 5 ст. 6 Федерального закона «О государственной регистрации юридических лиц и индивидуальных предпринимателей»).

Таким образом, смешанные режимы - разновидность правовых режимов информации о деятельности государственных органов, которые характеризуют права и обязанности должностных лиц, связанные с предоставлением информации, частично содержащей данные ограниченного доступа. При этом данные ограниченного доступа изымаются из предоставляемых данных, если не предусмотрено иное. В случаях, прямо предусмотренных законом, допустимо также совершение дополнительных процедур: распространение информащии ограниченного доступа в общественно значимых целях, ограничение возможности доступа необходимостью прохождения заявителем процедуры удостоверения личности.

${ }^{14} \mathrm{O}$ государственной регистрации юридических лиц и индивидуальных предпринимателей : фредер. закон от 8 августа 2001 г. № 129-ФЗ // Парламентская газета. 2001. 14 авг.

${ }^{15}$ Собрание законодательства Рос. Федерации. 2017. № 2 (ч. 1). Ст. 352.

${ }^{16}$ Например: Постановление Девятого арбитражного апелляционного суда от 27 июля 2017 г. № 09АП-31744/2017 по делу № А40-5250/17. Доступ из справ.-правовой системы «КонсультантПлюс».

${ }^{17}$ Рос. газета. 2021. 11 янв. 


\section{Библиографический список}

Beguin-Faynel C. "Rapport de synthèse». L'open data: une evolution juridique? / Mouriesse E. (dir.) // Revue générale du droit. Etudes et réflexions, 2018. № $11.45 \mathrm{p}$.

Canavaggio $P$. Vers un droit d'accès à l'information publique: les avancées récentes des normes et des pratiques. Rabat: UNESCO Office Rabat, 2014. 107 p.

Алексеев С. С. Общие дозволения и общие запреты в советском праве / под ред. Л. А. Плехановой. М. : Юрид. лит., 1989. 288 с.

Гунин Д. И. Транспарентность и тайна информации : теоретико-правовой аспект : автореф. дис. ... канд. юрид. наук. Екатеринбург, 2008. 24 с.

Калиалова Г. Г. Правовой режим информации ограниченного доступа : вопросы формирования понятийного аппарата // Вестник Удмуртского ун-та. 2016. Т. 26, вып. 4. С. 118-125.

Концепция Информационного кодекса Российской Федерации / под ред. И. Л. Бачило. М. : ИГП РАН, 2014. 192 с.

Терещенко Л. К. Правовой режим информации : автореф. дис. ... д-ра юрид. наук. М., 2011. 55 с.

Шалаева T. З. Правовой режим информационных ресурсов : проблемы правопонимания // Информационное право. 2014. № 4. С. 4-9.

\section{References}

Beguin-Faynel C. «Rapport de synthèse». L'open data: une evolution juridique? / Mouriesse E. (dir.) // Revue générale du droit. Etudes et réflexions, 2018. № $11.45 \mathrm{p}$.

Canavaggio $P$. Vers un droit d'accès à l'information publique: les avancées récentes des normes et des pratiques. Rabat: UNESCO Office Rabat, 2014. 107 p.

Alekseev S. S. General Permissions and General Restrictions in Soviet Law / L. A. Plekhanov (eds.). M., 1989. 288 p. (In Russ.)

Gunin D. I. Transparency and Secrecy of Information: Theoretical Legal Aspect. PHD thesis report (candidate of sciences). Ekaterinburg, 2008. 24 p. (In Russ.)

Kamalova G. G. Legal Regime of Restricted Access Information: Issues of Formation of Conceptual Apparatus // Udmurt University Herald. 2016. Vol. 26. Iss. 4. P. 118-125. (In Russ.)

The Concept of Informational Code of the Russian Federation / I. L. Bachilo (eds.) M., 2014. 192 p. (In Russ.)

Tereschenko L. K. Legal Regime of Information. PHD thesis report (doctor of sciences). M., 2011. 55 p. (In Russ.)

Shalaeva T. Z. Legal Regime of Information Resources: Problems of Legal Understanding // Information Law. 2014. № 4. P. 4 - 9. (In Russ.)

Национальньй исследовательский университет "Высшая школа экономикu»

Силкин В. В., стажер-исследователь Института права иифровой средь
National Research University "Higher School of Economics"

Silkin V. V., Research Trainee Institute for the Law of the Digital Environment 